\title{
Validity and Reliability of the Flourishing Scale in a Sample of Older Adults in Iran
}

This article was published in the following Dove Press journal:

Clinical Interventions in Aging

\author{
Zahra Fassih-Ramandi \\ Mohammad Ali Soleimani (iD ${ }^{2}$ \\ Kelly-Ann Allen (D) ${ }^{3}$ \\ Ozkan Gorgulu (iD) ${ }^{4}$ \\ Seyedeh Ameneh Motalebi (iD) ${ }^{2}$
}

'Student Research Committee, School of Nursing and Midwifery, Qazvin University of Medical Sciences, Qazvin, Iran; ${ }^{2}$ Social Determinants of Health Research Center, Research Institute for Prevention of NonCommunicable Diseases, Qazvin University of Medical Sciences, Qazvin, Iran; ${ }^{3}$ Faculty of Education, Monash University, Clayton, Australia;

${ }^{4}$ Department of Biostatistics and Medical Informatics, Faculty of Medicine, Ahi Evran University, Kirsehir, Turkey

Correspondence: Seyedeh Ameneh Motalebi

Social Determinants of Health Research Center, Research Institute for Prevention of Non-Communicable Diseases, Qazvin University of Medical Sciences, Qazvin, Iran Tel +982833338034

Fax +982833328212

Email ammotalebi@yahoo.com
Background: Flourishing is related to positive outcomes for physical and mental health, as well as overall wellbeing. The aim of the present study was to determine the validity and reliability of the Flourishing Scale (FS) among a sample of older participants in Iran.

Methods: In this validation study, 300 older people were selected by cluster sampling method. Data were collected using a checklist for demographic characteristics, the FS, and the Oxford happiness questionnaire. The validity (face, content, convergent, and construct) and reliability (Cronbach's alpha, test-retest) of the FS was evaluated in this cross-sectional study.

Results: The exploratory factor analysis demonstrated a one-dimensional structure consisting of 8 items with an eigenvalue of 3.583. The model had a good fit $\left[\chi^{2}=52.983, \mathrm{p}<0.001\right.$, $\chi^{2} / \mathrm{df}=2.944, \mathrm{GFI}=0.958, \mathrm{CFI}=0.915$, IFI $=0.949$, TLI $=0.919$, AGFI $=0.948$, and RMSEA $=0.081$, SRMR $=0.086]$ with all factor loadings greater than 0.5 and statistically significant. A test of concurrent validity showed a direct and significant association between the FS and the Oxford happiness questionnaire $(r=0.647, p<0.001)$. The results of the reliability tests confirmed that the values of Cronbach's alpha coefficient (0.819) and testretest $(0.821)$ were acceptable.

Conclusion: The Persian version of the FS demonstrated suitable validity and reliability among a sample of older participants.

Keywords: aging, factor analysis, flourishing, validity, reliability

\section{Introduction}

There is a growing body of literature that recognises the importance of successful and positive aging to cater to the growing aging population experienced by most countries around the world. ${ }^{1-4}$ According to estimates, older people 65 years and over have an annual global growth rate of $2.5 \%$ per year. ${ }^{5}$ About two thirds of the world's older people now live in developing countries such as Iran. ${ }^{6}$ According to Iran's 2016 census of population and housing, 9.3\% of the population is 60 years or older. $^{7}$ The rapid increase in the number of older people creates important concerns, especially in relation to their wellbeing and mental health, and how practitioners and clinicians can best support the strengths of a growing older population. ${ }^{8}$

Mental health and wellbeing are widely recognized as imperative dimensions of positive aging. ${ }^{9}$ Assisting people to flourish in the later stages of life has been found to have a positive impact on moderating depression, as well as increasing happiness and life satisfaction. ${ }^{10}$ Positive psychology - that is, the scientific study of human flourishing and an applied approach to optimal functioning - is a growing field of scientific enquiry. ${ }^{11,12}$ Positive psychology is concerned with human abilities and 
strengths and seeks to improve wellbeing through increasing positive feelings, behaviours, and thoughts, such as happiness, enjoyment, and optimism. ${ }^{13}$ Positive psychology interventions have been applied to a variety of contexts, including aged care, in order to help individuals thrive and improve their subjective wellbeing. ${ }^{14}$

Subjective wellbeing has been described as an individual's perception of the quality of their life and includes behavioral, emotional, and cognitive components. ${ }^{15}$ According to Diener ${ }^{16}$ subjective wellbeing has a wide variety of causal influences and is related to positive affect and life satisfaction and includes dimensions of happiness, purposefulness, and vitality. The feeling of vitality is closely linked to happiness and is one of the most important human experiences. ${ }^{17}$ Vitality is directly related to life satisfaction and inversely related to anxiety, depression, and other physical and mental disorders. ${ }^{18}$

Flourishing is a state of optimal functioning synonymous with high levels of positive emotions, wellbeing, mental health, and psychological and social wellbeing. ${ }^{19,20}$ Researchers have found human flourishing to have a range of benefits related to psychological and physical health, including reduced risk mortality. ${ }^{21,22}$ Therefore, the literature provides sufficient evidence for nurses and other healthcare professionals to be attuned to strategies and interventions that promote flourishing amongst older adults. $^{23}$

In the literature, several measures are available for flourishing assessment. The Flourishing Scale (FS $)^{24}$ is one of the most commonly used scales to examine flourishing. The scale consists of 8 items and is applicable to people 12 years or older. ${ }^{25}$ One of the benefits of this scale is that it is short and fluent with plain-language items that facilitate comprehension and suitability for older populations. In most of the studies that have been conducted on the FS, the sample consisted of adults or young adults. ${ }^{26-30}$ In our knowledge, only two studies specifically assessed the validity and reliability of the FS in an older adult sample. ${ }^{31,32}$ Momtaz, Hamid, Haron \& Bagat $^{32}$ and Didino, Taran, Baryshev \& Casati ${ }^{31}$ conducted studies on samples of community-dwelling older Malaysians and Russians, respectively. They found that the Russian and Malaysian version of the FS seemed to have good psychometric properties and could serve as a valid and reliable instrument to evaluate flourishing among Russian and Malaysian older adults.

In addition to the research conducted on the cultural differences in the way flourishing is perceived and understood, ${ }^{33}$ the psychometric properties of the FS have been studied in several countries including Spain, ${ }^{26}$ China,${ }^{34}$ the Netherlands, ${ }^{27}$ Japan, ${ }^{28}$ Turkey, ${ }^{35}$ Portugal, ${ }^{29}$ New Zealand, ${ }^{36}$ Singapore, ${ }^{24}$ Malaysia, ${ }^{32}$ Russia, ${ }^{31}$ and Italy ${ }^{37}$ with efficacious results. In Iran, the validity and reliability of this scale has been evaluated among Isfahan medical students and third-year female high school students. $^{25,30}$

Given that previous research has demonstrated that cultural influences play a significant role in people's perceptions of flourishing, ${ }^{33}$ it is necessary to validate the flourishing measurement instrument in Iran as well. A limited number of studies have been conducted to evaluate flourishing in Iranian older adults. ${ }^{15,38}$ These studies used the Ryan and Frederick subjective vitality scale for measuring flourishing, and no prior research, to the authors' knowledge, has psychometrically evaluated the FS in Iranian older adults. Therefore, the current study addresses this issues by providing the first validation of the FS in a sample of older participants in Iran. The level of psychological well-being in older adults is probably related to the local socio-economic and cultural situation and thus different countries could show different patterns.

\section{Methods}

In this validation study, 300 older people were selected using a multi-stage cluster sampling technique. In the first stage, the Qazvin city was divided into 5 clusters: North, South, East, West, and Center. Next, one mosque and one park were randomly selected from each cluster. Eligible older people were selected from these places using convenience sampling method. Participants were required to be 60 years or older and hold Iranian citizenship to be included in the study. Participants who reported having psychiatric problems (eg, Alzheimer's disease or other forms of dementia), a physical disability or limitation (eg, confinement to bed or wheel chair use), or terminal illness, were excluded from the study.

For a confirmatory factor analysis (CFA), 10 subjects per item, a minimum sample size of 300 , and a $\mathrm{KMO}>0.6$ is acceptable. ${ }^{39,40}$ The Oxford happiness questionnaire with 29 items had the most items among the scales used in the study. This indicates that $290(29 \times 10)$ subjects are needed for the Oxford happiness questionnaire. As this number is fewer than the minimum required for a CFA, 300 participants were used in this study. Furthermore, the KMO value was 0.852 , indicating that the data and sample size were adequate for the factor analysis. ${ }^{41}$ A total of 330 
participants were recruited to supply a final sample size of 300 . The study had a $90 \%$ response rate and $10 \%$ of the participants $(\mathrm{N}=30)$ felt tired and did not answer all the questions. Sampling continued until 300 participants were recruited in order to make up for the uncompleted responses. Data were collected through face-to-face interviews in the study places (mosques and parks) from April to August 2017 by one researcher.

\section{Instruments}

Data were collected through the use of a socio-demographic checklist, the FS, and the Oxford happiness questionnaire. The socio-demographic checklist elicited information from participants that included age, gender, marital status, employment details, and educational background.

\section{The Flourishing Scale}

Flourishing was measured by the FS which was developed by Diener et al (2010). The FS is an eight-item scale that has been designed to measure wellbeing in the domains of relationships, life purpose, self-esteem, and optimism. This scale assesses eudemonic dimensions of wellbeing. All 8 items of the scale are expressed in a positive direction and the responses are based on a 7-point Likert scale, ranging from "strongly disagree" to "strongly agree." A higher score indicates higher levels of respondents' wellbeing. . $^{2,36}$

The present study employed the use of the Persian version of the FS that was translated by Moradi Siah Afshadi M, Ghasemi ${ }^{30}$ based on World Health Organization protocol.

\section{The Oxford happiness questionnaire}

The Oxford happiness questionnaire was developed by Hills and Argyle (2002) ${ }^{42}$ at Oxford University to measure psychological wellbeing. It consists of 29 items rated on a 5-point Likert-type scale. According to Hone et al (2014), a total score of 48 or above is considered high. ${ }^{36}$ In the present study, the FS demonstrated an excellent internal reliability of consistency (Cronbach's alpha $=0.95$ ).

\section{Face Validity Assessment}

The face validity of the Persian version of the FS was evaluated both qualitatively and quantitatively. In order to evaluate the qualitative face validity of the Persian version of the FS, ten older adults assessed and commented on the appropriateness and relevance of the items. ${ }^{43}$ The scale was corrected according to their comments.

To assess the quantitative face validity, ten older adults were asked to determine the importance of the items on a 5-point Likert-type scale, ranging from "not important" to "completely important". The item impact score of the items was measured by using the following formula: impact score $=$ frequency $\times$ importance. In this formula, frequency is equal to the number of older people who regard each item as "important" or "completely important", noted by scores of ' 4 ' and ' 5 ', respectively. If the impact score of the item was greater than 1.5 , the item was suitable and was therefore maintained in the scale. ${ }^{44}$

\section{Content Validity Assessment}

The content validity of the Persian version of the FS was evaluated both qualitatively and quantitatively. For the qualitative content validity assessment, the Persian version of the FS was provided to fifteen experts in sociology, gerontology, psychology, and educational nursing, and they were requested to give feedback on the items of the scale in terms of wording, item allocation, grammar, and scaling. ${ }^{45}$ A final version of the scale was created after applying their comments.

The Content Validity Ratio (CVR) and the Content Validity Index (CVI) were used for the quantitative content validity analysis. CVR reflects whether the items are essential or not. Accordingly, fifteen experts were requested to rate the essentiality of the FS items on a 3-point Likert-type scale consisting of "not essential", "useful but not essential", and "essential". A higher score of CVR indicates greater agreement among the experts. The formula for the CVR is: $\mathrm{CVR}=(\mathrm{Ne}-\mathrm{N} / 2) /(\mathrm{N} / 2)$, where $\mathrm{Ne}$ is the number of experts indicating an item as "essential" and $\mathrm{N}$ is the total number of experts. ${ }^{43,46}$ According to Lawshe (1975), the minimum acceptable value for CVR is 0.49 when the number of experts is fifteen. ${ }^{47}$

The Items Content Validity Index (I-CVI) shows the degree to which the items of the intended scale are relevant. At the item level, I-CVI is calculated from the number of experts who rate the item as either a 3 or 4 on a 4-point likert scale, divided by the total number of experts. Judgment on each item is made as follows: when the number of experts is fifteen, the I-CVI value of 0.79 or greater shows the item to be appropriate; between 0.70 and 0.79 , it needs revision; and less than 0.70, it is eliminated. ${ }^{48}$ The CVR and I-CVI for the FS items are presented in Table 1.

\section{Construct Validity Assessment}

The construct validity of the Persian version of the FS was assessed by conducting an exploratory factor analysis (EFA) 
Table I The I-CVI and CVR for the Flourishing Scale Items

\begin{tabular}{|c|c|c|}
\hline \multirow[t]{2}{*}{ Items } & I-CVI & CVR \\
\hline & $\begin{array}{l}\text { Relevancy } \\
(1-4)\end{array}$ & $\begin{array}{l}\text { Essential } \\
(I-3)\end{array}$ \\
\hline I. I lead a purposeful and meaningful life & 0.86 & 1.00 \\
\hline $\begin{array}{l}\text { 2. My social relationships are supportive and } \\
\text { rewarding }\end{array}$ & 0.80 & 0.60 \\
\hline $\begin{array}{l}\text { 3. I am engaged and interested in my daily } \\
\text { activities }\end{array}$ & 0.93 & 1.00 \\
\hline $\begin{array}{l}\text { 4. I actively contribute to the happiness and } \\
\text { wellbeing of others }\end{array}$ & 0.93 & 0.73 \\
\hline $\begin{array}{l}\text { 5. I am competent and capable in the } \\
\text { activities that are important to me }\end{array}$ & 0.73 & 0.60 \\
\hline 6. I am a good person and live a good life & 0.80 & 0.60 \\
\hline 7. I am optimistic about my future & 1.00 & 0.86 \\
\hline 8. People respect me & 0.73 & 0.60 \\
\hline
\end{tabular}

Notes: Copied from Diener, E., Wirtz, D., Tov, W., Kim-Prieto, C., Choi, D., Oishi, S., \& Biswas-Diener, R. (2009). New measures of well-being: Flourishing and positive and negative feelings. Social Indicators Research, 39, 247-266.

Abbreviations: I-CVI, items content validity index; CVR, content validity ratio.

with Varimax rotation. First, the adequacy of using EFA was assessed through the Kaier-Meyer-Olkin (KMO) criterion and the Bartlett Sphericity test. Recommended KMO values should be equal to or above 0.60 , and the Bartlett Chi-Square test should be statistically significant to support this type of statistical analysis. ${ }^{49}$ The number of components was determined based on eigenvalues and a scree plot. Items with absolute loading values of 0.30 or greater were regarded as appropriate. $^{50}$ Second, a confirmatory factor analysis (CFA) was carried out to confirm the EFA. Due to the covariance matrix, Maximum Likelihood (ML) method was adopted. Reporting multiple fit indices to estimate the good-fitting models is necessary to evaluate consistency among different indices. ${ }^{49}$ Various indices to evaluate fit were used: ChiSquare $\left(\chi^{2}\right)$, Chi-Square/degrees of freedom $\left(\chi^{2} / \mathrm{df}\right)$; an adjusted model showing a value between 2 and 3 , although values up to 5 can be accepted as evidence of adequacy; GFI and AGFI (values near 0.90 are recommended); CFI, values close to or higher than 0.90 suggest an adequate fit; TLI, values close to 1.00 are satisfactory, but those between 0.80 and 0.90 are also acceptable; SRMR, values less than 0.5 are considered satisfactory, however values close to 0.8 may also be acceptable; and RMSEA, values between 0.05 and 0.08 are recommended, accepting those up to $0.10{ }^{51}$

\section{Reliability Assessment}

The reliability of the Persian FS was assessed by calculating Cronbach's alpha and test-retest.

\section{Ethical Consideration}

The study was approved by the Ethics Committee of Qazvin University of Medical Sciences, Qazvin, Iran (IR.QUMS.REC.1396.494). The participants were informed about the objectives, procedures, potential benefits, and drawbacks of the study. Furthermore, they were instructed that participation was voluntary and that confidentiality of the obtained information was guaranteed. The participant consent was written informed consent and this study was conducted in accordance with the Declaration of Helsinki.

\section{Statistical Analysis}

We used Statistical Package for Social Sciences version 21.0 software for Windows (IBM SPSS Statistics for Windows, Version 21.0. Armonk, NY: IBM Corp., USA) and AMOS for statistical calculations. The normal distributions of the data were examined and approved by skewness and kurtosis.

\section{Results}

The mean age of the participants of the present study was $66.1 \pm 6.5$ years old, ranging from 60 to 98 . The majority of the participants were male $(N=164,54.7 \%)$, married $(N=$ 236, 78.7\%), retired $(N=135,45.0 \%)$, and literate $(N=$ $241,80.3 \%$ ) (Table 2).

Table 3 reports the results of the Exploratory Factor Analysis (EFA) of the 300 participants. The Kaiser-MeyerOlkin value $(\mathrm{KMO}=0.852)$ and the results of Bartlett's test of sphericity (691.796, $d f=28, p<0.001)$ indicated that the data were suitable for conducting the EFA. Using the scree plot (Figure 1) and eigenvalue $>1$ criteria, the EFA revealed one factor comprised of 8 items, accounting for $44.792 \%$ of the variance.

As reported in Table 3, Cronbach's alpha (0.819) demonstrated good internal consistency among the items. The result of the test-retest reliability $(0.821)$ was also in the acceptable range.

The results of a Pearson correlation analysis showed a significant positive relationship between the FS and the Oxford happiness questionnaire $(r=0.647, p<0.001)$, providing support for the concurrent validity of the scale. 
Table 2 Demographic Profiles of the Participants

\begin{tabular}{|l|l|}
\hline Characteristics & N (\%) \\
\hline $\begin{array}{l}\text { Gender } \\
\text { Male }\end{array}$ & $164(54.7 \%)$ \\
Female & $136(45.3 \%)$ \\
\hline Marital Status & \\
Single & $64(21.3 \%)$ \\
Married & $236(78.7 \%)$ \\
\hline Education & \\
Illiterate & $59(19.7 \%)$ \\
Primary & $31(10.3 \%)$ \\
Under Diploma & $117(39.0 \%)$ \\
Diploma & $54(18.0 \%)$ \\
Academic & $39(13.0 \%)$ \\
\hline Job & $36(32.0 \%)$ \\
Retired & $32(10.7 \%)$ \\
Employed & $135(45.0 \%)$ \\
Housewife & 37 (12.3\%) \\
\hline
\end{tabular}

Abbreviation: $\mathrm{N}$, number.

The CFA sought to test the structure of the EFA, grouping the 8 items of the FS into a single factor. The main results of this model are shown in Figure 2. The model was shown to be a good fit $\left[\chi^{2}=52.983, p<0.001\right.$, $\chi^{2} / d f=2.944, \mathrm{GFI}=0.958, \mathrm{CFI}=0.915, \mathrm{IFI}=0.949$, TLI $=0.919$, AGFI $=0.948$, and RMSEA $=0.081$, SRMR $=$ 0.086]. Average variance extracted of the construct was 0.443 , which is due to the conservativeness of this measure.

\section{Discussion}

The purpose of this study was to determine the psychometric properties of the Persian version of the FS amongst older participants in Iran. Exploratory and confirmatory

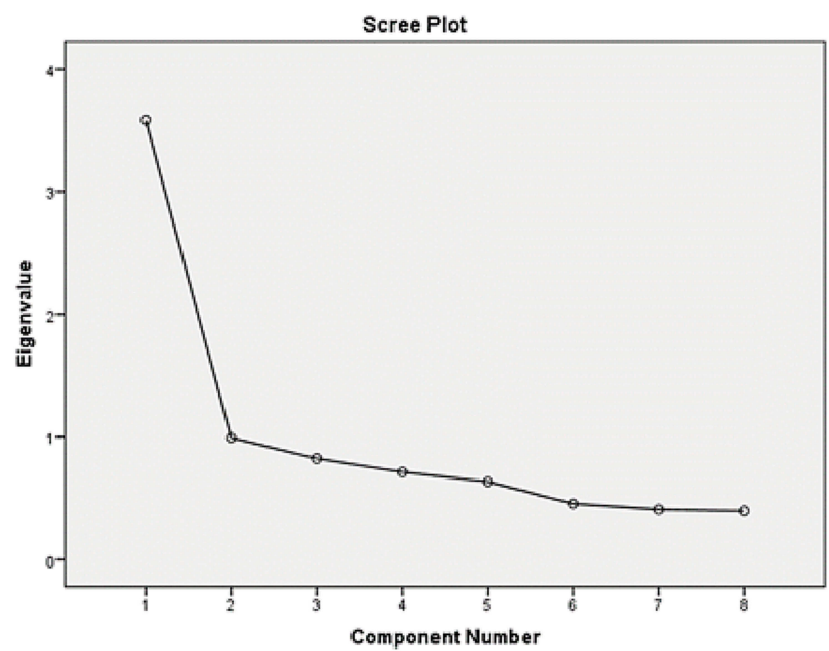

Figure I Scree plot of exploratory factor analysis.

factor analysis methods were used to investigate the underlying structure of this scale. The results of the exploratory factor analysis showed that the FS is a one-dimensional structure accounting for $44.792 \%$ of the variance among the older adults. Results from national ${ }^{25}$ and international $^{24,26,29,32,34,35}$ studies on a range of age groups have also confirmed the one-dimensionality of the scale. For example, Diener E, Wirtz D (24) reported the FS to have a one-dimensional structure explaining $53 \%$ of the variance. Furthermore, Moradi Siah Afshadi et al (2015) demonstrated a one-factor structure explaining $46 \%$ of the variance with 200 medical students at the Isfahan University of Medical Sciences. ${ }^{30}$ Momtaz et al $^{32}$ also recognized the presence of one strong factor with an eigenvalue above 1 (5.86), explaining $73.20 \%$ of the variance among older Malaysians. Likewise, Didino et $\mathrm{al}^{31}$ reported one strong factor with an eigenvalue of 3.56, explaining $37 \%$ of the total variance among older Russians.

Table 3 Factor Structure of the Flourishing Scale

\begin{tabular}{|c|c|c|c|c|c|c|c|}
\hline Items & Mean士SD & Component & $\begin{array}{l}\text { Factor } \\
\text { Loading }\end{array}$ & Eigenvalue & $\begin{array}{l}\text { Explained } \\
\text { Variance }\end{array}$ & $\begin{array}{l}\text { Cronbach's } \\
\text { Alpha }\end{array}$ & $\begin{array}{l}\text { Average Variance } \\
\text { Extracted }\end{array}$ \\
\hline Item 3 & $5.86 \pm 1.49$ & 0.790 & 0.760 & 3.583 & 44.792 & 0.819 & 0.443 \\
\hline Item 6 & $5.99 \pm 1.20$ & 0.787 & 0.747 & & & & \\
\hline Item 7 & $5.76 \pm 1.59$ & 0.707 & 0.654 & & & & \\
\hline Item I & $5.60 \pm 1.60$ & 0.643 & 0.586 & & & & \\
\hline Item 5 & $6.11 \pm 1.12$ & 0.643 & 0.578 & & & & \\
\hline Item 4 & $6.31 \pm 1.13$ & 0.636 & 0.563 & & & & \\
\hline Item 8 & $6.41 \pm 1.12$ & 0.564 & 0.487 & & & & \\
\hline Item 2 & $5.73 \pm 1.61$ & 0.539 & 0.454 & & & & \\
\hline
\end{tabular}

Abbreviations: SD, standard deviation. 




Figure 2 The final structural model of the Persian version of the FS among a sample of older adults in Iran.

A CFA model was applied to determine the validity of the Persian version of the FS in the present study. The results showed that all fitness indicators were in suitable ranges in line with previous research. Giuntoli et $\mathrm{al}^{37}$ reported good fitness characteristics for the Italian version of the FS. However, the CFA of the Bahasa Melayu version of the FS indicated satisfactory model fit for older people after modifying the model by correlating the errors. ${ }^{32}$ Furthermore, in a study among Russian older adults, the model showed a better fit after error correlations were used, and all indices had satisfactory values within the acceptable range. ${ }^{31}$ Tong and Wang (2017) ${ }^{34}$ showed a better fit after the modification index using one error covariance in the Chinese version of the FS.

In the present study, items 2 ("My social relationships are supportive and rewarding") and 8 ("People respect me") showed the lowest factor loadings. Similarly, in the study by Hassani and Nadi (2015), these two items showed the lowest factor loading compared to the other items of the scale. ${ }^{25}$ The weak factor loading on item 2 can be due to the ambiguity of this question, which may result in the participants interpreting the phrases in different ways. Regarding item 8, it may be related to the Iranian culture, which believes that a positive response to this question is a sign of selfishness and being far from humble. Because of this, respondents-especially older people - may refuse to give a truthful answer.
Item 3, "I am engaged and interested in my daily activities", had the highest factor loading (0.76), as those who feel more energetic are more likely to engage in daily activities, and would be expected to perceive physical activity as easier. Likewise, Ju (2017) indicated that physical activity was positively associated with both meaning in life and subjective vitality. ${ }^{52}$ Other research has shown that participation in a physical activity program has positive effects on participants' sense of vitality due to the mediation of physical functioning. ${ }^{53}$

The results of this study showed a significant and direct correlation between flourishing and happiness that is consistent with the results of studies by Keshavarz et al $(2005)^{18}$ and Diener et al (2010). ${ }^{24}$ One reason for this finding may be that both constructs (flourishing and happiness) are associated with positive emotions. Also, it has been established that flourishing increases happiness through improving physical health, mobility, mental health, and social functioning. ${ }^{18}$ Therefore, using the FS could be an appropriate alternative to the Oxford happiness questionnaire in the field of older adult research.

The results of the present study showed that the reliability tests (Cronbach's alpha and test-retest) were in the acceptable ranges. It is clear that when Cronbach's alpha is closer to 1 , the internal consistency of the items will be more homogeneous. It also indicates the scale's items are measuring a similar concept, and that there is no 
conceptual dispersion. In previous studies on different age groups in Singapore, ${ }^{24}$ New Zealand, ${ }^{36}$ France, ${ }^{54}$ Italy, ${ }^{55}$ Japan, ${ }^{28}$ Turkey, ${ }^{35}$ Portugal, ${ }^{29}$ and Iran, ${ }^{25,30}$ Cronbach's alpha coefficients were reported from 0.80 to 0.91 , which is within the acceptable range (ie, above 0.7 ). Therefore, it can be assumed that the items of the scale assess a similar flourishing concept. The test-retest reliability was 0.70 with a two-week interval, which is in accordance with the results of the study by Diener et al (2010) in the USA (0.70), which was performed with a one-month interval. ${ }^{24}$ Furthermore, the test-retest of another study in Japan (2014) on 336 students aged 18 to 24 years with a one-month interval was equal to $0.87 .^{28}$ Hassani and Nadi (2015) estimated the test-retest reliability coefficient of a vitality questionnaire to be 0.83 on 103 students with a two-week interval. ${ }^{25}$ As a whole, the results of all previous studies showed the optimal level of test-retest reliability. The difference in the amount of correlation coefficients in the aforementioned studies can be attributed to the sample under investigation, as the cognitive functioning of the students may be significantly better than older participants.

\section{Limitations}

The sample of this study was comprised of community-dwelling older adults, which limits the potential to generalize the results to older people living in institutions. A second limitation of the study relates to the use of self-report questionnaires to elicit information from participants. Although partially addressed through inclusion criteria, the cognitive capacity of respondents at the time the study took place may have had some influence on the results of the study. Another limitation of the study is that only the older people in public places such as parks and mosques were studied, and those unable to be present in these places (eg, due to illness or disability) were not examined. It is also reasonable to suggest the older adults residing in the city of Qazvin may not necessarily represent all older adults in Iran.

\section{Future Research}

Findings of the present study suggest the FS is an efficacious tool for evaluating flourishing in older populations in Iran. Given that the tool can be used for children as young as 12 , future research should consider evaluating the psychometric properties of the Persian version of the tool for Iranian youth. There has been no previous research that has investigated this cohort and a reliable and valid measure of this type has great potential for informing proactive interventions concerned with mental health and wellbeing in secondary school. ${ }^{56,57}$ There is also growing evidence on the role of euthymia on positive aging and flourishing. ${ }^{58,59}$ Therefore, it is suggested that future studies use the FS in conjunction with the Euthymia Scale. Additionally, the clinimetric properties of the FS, consisting of clinical validity, utility, sensitivity, and scalability were not evaluated in this study. It is suggested that future studies evaluate the clinimetric features of the FS, as this scale can be reasonably used amongst older adults in a clinical setting.

\section{Conclusions}

This study confirmed adequate psychometric properties and factor structure of the FS in a sample of older Iranian participants. Findings suggest that the scale can be used as a valid and reliable tool for the assessment of flourishing experienced by Iranian older adults. The ease of implementation (and brief number of items) provides researchers and clinicians with a time-saving tool that could be used extensively to assess human flourishing in Iran.

\section{Acknowledgments}

We would like to extend our deep gratitude to the older people who helped to make this research possible.

\section{Disclosure}

The authors report no conflicts of interest in this work.

\section{References}

1. Bahrami N, Moradi M, Soleimani M, Kalantari Z, Hosseini F. Death anxiety and its relationship with quality of life in women with cancer. Iran J Nurs. 2013;26(82):51-61.

2. Nia HS, Sharif SP, Lehto RH, et al. Psychometric properties of the persian version of death depression scale-revised in Iranian patients with acute myocardial infarction. Iran J Psychiatry. 2017;12(3):172.

3. Yaghoobzadeh A, Gorgulu O, Yee B-L, et al. A model of aging perception in Iranian elders with effects of hope, life satisfaction, and socioeconomic status: a path analysis. J Am Psychiatr Nurses Assoc. 2018;24(6):522-530. doi:10.1177/1078390317753676

4. Yaghoobzadeh A, Sharif Nia H, Pahlevan Sharif S, et al. Role of sex, socioeconomic status, and emotional support in predicting aging perception among older adults. Int J Aging Human Dev. 2018;87 (1):77-89. doi:10.1177/0091415017727211

5. Aliakbari Dehkordi M, Peymanfar E, Mohtashami T, Borjali A. The comparison of different levels of religious attitude on sense of meaning, loneliness and happiness in life of elderly persons under cover of social welfare organisation of urmia City. Salmand. 2015;9 (4):297-305.

6. Sheykhi MT. State of widowhood in Iran: challenges of ageing spouses. Int J Ageing Dev Countries. 2016;1(1):54-67.

7. SCo I. Population and housing census in 2016. statistic center of Iran; 2016. Available from http://wwwSCIorg. 
8. Iranagh JA, Motalebi SA, Mohammadi F. A theoretically based behavioral nutrition intervention for elderly women: a cluster randomized controlled trial. Int $J$ Gerontology. 2018;12(2):127-132. doi:10.1016/j.ijge.2017.08.007

9. Halaweh H, Dahlin-Ivanoff S, Svantesson U, Willén C. Perspectives of older adults on aging well: a focus group study. J Aging Res. 2018;2018.

10. Nojabaee A, Salehmoghaddam AR, Mazlom SR, Asgharipour N, Mohajer S. Effect of flourishing promotion program on social health in the elderly. Evidence Based Care. 2018;8(2):39-48.

11. Seligman MEP, Rashid T, Parks A. Positive psychotherapy. US National Lib Med National Inst Health Search Database. 2006;61 (8):774-788

12. Furlong MJ, Gilman R, Huebner ES. Handbook of Positive Psychology in Schools. 2014. 2nd Edition. New York, USA: Routledge, Taylor and Francis Group.

13. Seligman ME, Steen TA, Park N, Peterson C. Positive psychology progress: empirical validation of interventions. Am Psychol. 2005;60 (5):410. doi:10.1037/0003-066X.60.5.410

14. Woodworth RJ, O’Brien-Malone A, Diamond MR, Schüz B. Happy days: positive psychology interventions effects on affect in an N-of-1 trial. Int J Clin Health Psychol. 2016;16(1):21-29. doi:10.1016/j. ijchp.2015.07.006

15. Arabzadeh M, Pirsaghi F, Kavosian J, Amani K, Abdollahpour Y. Investigating the structural relationship between basic psychological needs and subjective well-being with mental health in older adults. J Gerontol. 2017;2(2):1-10. doi:10.29252/joge.2.2.1

16. Diener E. Subjective well-being. Psychol Bull. 1984;95(3):542. doi:10.1037/0033-2909.95.3.542

17. Hamid N, Vatankhah M, Mehrabizadeh-Honarmad M. The efficacy of quality of life group training on happiness and vitality of aged men. J Urmia Univ Med Sci. 2013;24(10):800-811.

18. Keshavarz A, Molavi H, Kalantari M. The relationship between vitality and demographic variables with happiness in Isfahan population. Q J p Sychol Stud. 2009;4(4):45-64.

19. Keyes CL. The mental health continuum: from languishing to flourishing in life. J Health Soc Behav. 2002;43(2):207-222. doi:10.2307/ 3090197

20. Huppert F, So T. Flourishing across Europe: application of a new conceptual framework for defining well-being. Soc Indic Res. 2013;110(3):837-861. doi:10.1007/s11205-011-9966-7

21. Keyes CL. Mental health in adolescence: is America's youth flourishing? Am j Orthopsychiatry. 2006;76(3):395-402. doi:10.1037/ 0002-9432.76.3.395

22. Keyes CL. Promoting and protecting mental health as flourishing: a complementary strategy for improving national mental health. Am Psychol. 2007;62(2):95. doi:10.1037/0003-066X.62.2.95

23. Sorrell JM. Promoting human flourishing in aging. J Psychosoc Nurs Ment Health Serv. 2017;55(10):27-30. doi:10.3928/0279369520170919-03

24. Diener E, Wirtz D, Tov W, Kim-Prieto C, Choi DW, Oishi S, BiswasDiener R. New measures of well-being: Flourishing and positive and negative feelings. Social Indicators Research. 2009;39:247-266.

25. Hassani M, Nadi MA. Investigating psychometric properties and standardization of the flourishing scale among female students of the third grade of high school. Positive Psychol. 2016;2(1):63-74.

26. Pozo-Muñoz C, Garzón-Umerenkova A, Bretones-Nieto B, Ligia-Charry C. Psychometric properties and dimensionality of the "Flourishing Scale" in Spanish-speaking population. EJREP. 2016;14(1):175-192.

27. Schotanus-Dijkstra M, Ten Klooster PM, Drossaert CHC, et al. Validation of the Flourishing Scale in a sample of people with suboptimal levels of mental well-being. BMC Psychol. 2016;4 (12):10. doi:10.1186/s40359-016-0116-5

28. Sumi K. Reliability and validity of Japanese versions of the flourishing scale and the scale of positive and negative experience. Soc Indic Res. 2014;118(2):601-615. doi:10.1007/s11205-013-0432-6
29. Silva AJ, Caetano A. Validation of the flourishing scale and scale of positive and negative experience in Portugal. Soc Indic Res. 2013;110 (2):469-478. doi:10.1007/s11205-011-9938-y

30. Moradi Siah Afshadi M, Ghasemi N, Ghamarani A. Evaluating the validity and reliability of flourishing scale and determining the relation between flourishing and academic achievement in students of medicine school. Iran J Med Educ. 2015;15:330-337.

31. Didino D, Taran EA, Barysheva GA, Casati F. Psychometric evaluation of the Russian version of the flourishing scale in a sample of older adults living in Siberia. Health Qual Life Outcomes. 2019;17 (1):34. doi:10.1186/s12955-019-1100-6

32. Momtaz YA, Hamid TA, Haron SA, Bagat MF. Flourishing in later life. Arch Gerontol Geriatr. 2016;63:85-91. doi:10.1016/j.archger. 2015.11.001

33. Weziak-Bialowolska D, McNeely E, VanderWeele T. Human flourishing in cross cultural settings. Evidence from the US, China, Sri Lanka, Cambodia And Mexico. Front Psychol. 2019;10:1269. doi:10.1007/s10648-014-9258-2

34. Kit Tong K, Wang YY. Validation of the flourishing scale and scale of positive and negative experience in a Chinese community sample. PLoS One. 2017;12(8):10.

35. Telef B The validity and reliability of the turkish version of the psychological well-being. Paper presented at the 11th National Congress of Counseling and Guidance. 2001; Selçukİzmir, Turkey.

36. Hone L, Jarden A, Schofield G, Duncan S. The impact of operational definitions on the prevalence of high levels of wellbeing. Int $J$ Wellbeing. 2014;4(1):62-90. doi:10.5502/ijw.v4i1.4

37. Giuntoli L, Ceccarini F, Sica C, Caudek C. Validation of the Italian Versions of the Flourishing Scale and of the Scale of Positive and Negative Experience. SAGE Open. 2017;7(1):2158244016682293. doi: $10.1177 / 2158244016682293$

38. Sharifi J, Shahbazi M, Goodarzian M. Effectiveness of Hope Therapy on Life Satisfaction and Vitality of Elderly Women. 2015.

39. Zahra B-M, Sara E-S, Ebadi A, Alireza -N-N, Mohraz M. Development and psychometric evaluation of a reproductive health assessment scale for HIV-positive women. Shiraz E-Med J. 2016;17 (6):8.

40. Yong AG, Pearce S. A beginner's guide to factor analysis: focusing on exploratory factor analysis. Tutor Quant Methods Psychol. 2013;9 (2):79-94. doi:10.20982/tqmp.09.2.p079

41. Harrington D. Confirmatory Factor Analysis. Oxford university press; 2009.

42. Hills P, Argyle M. The oxford happiness questionnaire: a compact scale for the measurement of psychological well-being. Pers Individ Dif. 2002;33(7):1073-1082. doi:10.1016/S0191-8869(01)00213-6

43. Molaei M, Etemad K, Taheri Tanjani P. Prevalence of elder abuse in Iran: a systematic review and meta analysis. Iran J Ageing. 2017;12 (2):242-253.

44. Hajizadeh E, Asghari M. Statistical Methods and Analyses in Health and Biosciences a Research Methodological Approach. Tehran: Jahade Daneshgahi Publications; 2011:395.

45. Colton D, Covert R. Designing and Constructing Instruments for Social Research and Evaluation. John Wiley \& Sons; 2007.

46. DeVon HA, Block ME, Moyle-Wright P, et al. A psychometric toolbox for testing validity and reliability. J Nurs Scholarship. 2007;39 (2):155-164. doi:10.1111/j.1547-5069.2007.00161.x

47. Lawshe C. A qualitative approach to content validity. Pers Psychol. 1975;25(4):563-575. doi:10.1111/j.1744-6570.1975.tb01393.x

48. Yaghmaie F. Content validity and its estimation. J Med Educ. 2003;3 (1):25-27.

49. Tabachnick BG, Fidell LS. Using Multivariate Statistics. 6th ed. Boston. Ma: Pearson; 2013.

50. Saggino A, Kline P. Item factor analysis of the Italian version of the death anxiety scale. $J$ Clin Psychol. 1996;52(3):329-333. doi:10.1002/(SICI)1097-4679(199605)52:3<329::AID-JCLP11>3.0. $\mathrm{CO} ; 2-\mathrm{K}$ 
51. da Fonseca PN, da Silva Nascimento B, Macêdo Barbosa LHG, Vione KC, Veloso Gouveia V. Flourishing Scale: Evidence of Its Suitability to the Brazilian Context. 2015.

52. Ju H. The relationship between physical activity, meaning in life, and subjective vitality in community-dwelling older adults. Arch Gerontol Geriatr. 2017;73:120-124. doi:10.1016/j.archger.2017.08.001

53. Liubicich ME, Candela F, Magistro D, Rabaglietti E, Ortega E. Physical Functioning: The Mediating Effect on ADLs and Vitality in Elderly Living in Residential Care facilities. "Act on Ageing". A pilot study; 2012.

54. Arnaud V, Laurent S, Sung Cheo J, Laure G. Psychological flourishing: validation of the French version of the Flourishing Scale and exploration of its relationships with personality traits. Pers Individ Dif. 2016;88:1-15. doi:10.1016/j.paid.2015.08.027
55. Fabio AD. Flourishing Scale: first contribution to the validation of the Italian version.. J Res Intervention. 2016;9:1-17.

56. Waters L, Barsky A, Ridd A, Allen K. Contemplative education: a systematic, evidence-based review of the effect of meditation interventions in schools. Educ Psychol Rev. 2015;27(1):103-134.

57. Allen K, Boyle C, Roffey S, editors. Creating a Culture of Belonging in a School Context. British Psychological Society; 2019.

58. Carrozzino D, Svicher A, Patierno C, Berrocal C, Cosci F. The euthymia scale: a clinimetric analysis. Psychother Psychosom. 2019;88(2):119-121. doi:10.1159/000496230

59. Fava GA, Guidi J. The pursuit of euthymia. World Psychiatry. 2020;19(1):40-50. doi:10.1002/wps.20698
Clinical Interventions in Aging

\section{Publish your work in this journal}

Clinical Interventions in Aging is an international, peer-reviewed journal focusing on evidence-based reports on the value or lack thereof of treatments intended to prevent or delay the onset of maladaptive correlates of aging in human beings. This journal is indexed on PubMed Central, MedLine, CAS, Scopus and the Elsevie
Dovepress

Bibliographic databases. The manuscript management system is completely online and includes a very quick and fair peer-review system, which is all easy to use. Visit http://www.dovepress.com/ testimonials.php to read real quotes from published authors. 